\section{Pharmacological and psycho-social interventions in management of depression}

Sir,

The article by Balhara and Verma, ${ }^{[1]}$ in the latest issue of Journal of Social Health and Diabetes titled - "Review of psycho-social interventions in management of depression in diabetes," is well written with an exhaustive review of literature.

There is a $250 \%$ increase in the use of psychotropic medications in adolescents from 1994 to 2001 suggesting that people have become more comfortable with using drug therapy as a treatment for mental disorders. ${ }^{[2]}$ And, this trend follows in a developing country like India where the numbers of psychologist available for the psycho-social interventions are very few; hence, the mainstay of treatment for depression still remains the pharmacotherapy. A disadvantage of psychotherapy is that it typically takes longer than drug therapy to produce benefits that are noticeable to the person receiving treatment - six to eight weeks or longer for psychotherapy, compared with four to six weeks for medication. Also, psychotherapy alone is not effective in people with severe depression. ${ }^{[3]}$

Prescription anti-depressants are effective at all levels of severity, ${ }^{[4]}$ whereas different types of psychotherapy are also effective but for managing only mild to moderate depression.

In our Indian set up, wherein psychiatric disorders still has a taboo placed on it, the concept of psychological interventions is severely disregarded. Those who do visit the psychiatrist, come with a mind set of being treated with drugs and also an early recovery. The regularity of followups, which would be required in psycho-social treatment modality, is also lost on the patients as they prefer a long follow up. The compliance issues, which are associated with the negligence, low awareness about illness, and social taboo, are also a major thing to be considered. It would be difficult to restore the improvement attained by the therapy in case of erratic compliance, wherein the medications will be able to give an early relief, thus improving the compliance. The sessions conducted are usually of about 30-45 minutes, which are long. Low education standard is another hindrance in the instructions given to patients during therapy and in patients who would require selfassessment exercises.

Many patients are seeking medication from their general practitioners rather than having to see a psychiatrist. But, it may not be possible for a patient to have cognitive behavior therapy (CBT) from an untrained person. The effectiveness of therapy may depend on a high level of therapist experience, but that may not be the case of treatment with drugs. ${ }^{\text {[6] }}$ The decision to use psycho-social treatment requires consideration of local psychotherapy resources, relative expense of treatments, and response to past therapies. ${ }^{[7]}$

Moreover, in severe depression with a high of suicide, the instant effect of pharmacotherapy can save lives while psychotherapy will be rendered helpless. The transference, which a patient might develop with the therapist further, can cause stress and difficulty in ending the sessions. The cultural and religious bounds would prevent a patient from certain therapies.

Hence, a combination of both psycho-social and pharmacological treatment will be more effective as they both augment the effect of each other, but alone psychosocial treatment may not be as effective.

Manish Bathla, Manpreet Singh

Department of Psychiatry M M Institute of Medical Sciences and Research, Mullana, India

Corresponding Author: Dr. Manish Bathla, 782 Sector 13, Karnal - 132001, India. E-mail: mentaldental@rediffmail.com 


\section{REFERENCES}

1. Balhara YP, Verma R. Management of Depression in diabetes: A review of psycho-social interventions. J Soc Health Diabetes 2013;1:22-6.

2. Thomas C, Conrad P, Casler R, Goodman E. Trends in the use of psychotropic medications among adolescents 1994 to 2001. Psychiatr Ser 2006;57:63-9.

3. Available from: http://www.johnshopkinshealthalerts.com/alerts/ depression_anxiety/psychotherapy_3926-1. html. [Last accessed on 2013 Jul 17].

4. Available from: http://www.ahrq.gov/clinic/tp/deprtp.htm. [Last accessed on 2013 Jul 17]

5. Geddes J, Butler R, Hatcher S, Cipriani A, Price J, Carney S, et al. Depressive disorders. Clin Evid 2004;12:1391-436.

6. DeRubeis RJ, Hollon SD, Amsterdam JD, Shelton RC, Young $\mathrm{PR}$, Salomon RM, et al. Cognitive therapy vs medications in the treatment of moderate to severe depression. Arch Gen Psychiatry 2005;62:409-16.

7. Spencer DC. Counseling or Antidepressants for Treating Depression? Am Fam Physician 2005;72:2309-10.

8. Grohol J. Depression treatment: Psychotherapy, medication or both? Psych Central. 2008. Available from: http://psychcentral. com/lib/depression-treatment-psychotherapy-medication-orboth/0001521. [Last retrieved on 2013 Jul 29].

\begin{tabular}{|l|l|}
\hline \multicolumn{2}{|c|}{ Access this article online } \\
\hline Quick Response Code: & Website: \\
\hline & www.joshd.net \\
\hline & \\
\hline
\end{tabular}

